\title{
Knowledge Sharing and Creation: The Bricks and Mortar of Intra-organisational Co-operation within a Scottish Local Authority
}

\author{
Barbara Bardzki and Vivien Reid \\ Division of Business Information Management \\ Glasgow Caledonian University \\ Cowcaddens Road \\ Glasgow G4 0BA, Scotland, UK \\ $\{$ B.Bardzki, V.Reid\}@gcal.ac.uk
}

\begin{abstract}
Plans to modernize government processes and practices are leading to a reconsideraton of how to manage the vast range of knowledge resources that are found within the public sector. The theory and practice of Knowledge Management (KM) are found to be increasingly applied. This paper aims to explore the problems surrounding KM in one department of a large local authority in Scotland, namely the Building Services Department within Glasgow City Council. The discussion recognizes the importance of information age governance and that successful KM involves more than just the implementation of systems. These initial findings relate to research undertaken in late 2002 before a major reorganization of Building Services.
\end{abstract}

\section{Introduction}

Plans to modernise government processes and practices are leading to a reconsideration of how to manage the vast range of knowledge resources that are found within the public sector. Much of the work in the public sector revolves around the use and interpretation of information and knowledge. With the quantity and multiplicity of types of information being held and used within the public sector, not to mention the numbers of people employed, managing knowledge is a difficult task. One consequence of this is that concepts of Knowledge Management (KM) are increasingly being applied.

$\mathrm{KM}$, although a concept which has many differing views and interpretations, is generally understood to be an organised and systematic attempt by organisations to transform the acquisition, preservation and sharing of knowledge to improve their performance. KM attempts to address the problems of the distribution of knowledge across organisations. However, some see KM as the 'next stage' in ICT development, designing software solutions to managing knowledge. Others see is as people management, with an emphasis on the development of social relations to enhance knowledge sharing and create 'communities of practice'.

Managing information and knowledge is critical and central to the way in which the public sector functions, and is also important in helping to achieve some of the 
reforms that are currently being put forward within the public sector. For example, knowledge sharing and $\mathrm{KM}$ strategies can help to promote trust and increase the transparency of decision-making situations. The internal processes of government are increasingly relying on technology to communicate and so it is essential that different departments and groups learn to impart information and knowledge to each other and to, also, establish trust and accountability.

This paper aims to explore the problems surrounding KM in one department of a large local authority in Scotland, namely the Building Services Department within Glasgow City Council. Taking a knowledge focus can improve the processes of government but can an ICT enabled system alone improve the decision-making and control within such a department? Or does it take more than a piece of software to implement a KM project? This particular group is one that has undergone many organisational changes in the recent past and although could be described as a community of practice, in that there is much knowledge and expertise within the team which could improve work practices, there appears to be little evidence of knowledge sharing.

The discussion will consider $\mathrm{KM}$ as an important feature of information age governance and address some of the difficulties that need to be overcome if KM is to be successfully implemented. The paper will, firstly, briefly outline the evolution of KM before exploring the application of KM within the public sector in particular. It then moves on to discuss KM within Building Services and whether they can creatively use ICTs to underpin a KM strategy, to serve the needs of both internal and external stakeholders. The paper addresses KM at the micro level of a department in local government but some of the issues may well also be relevant to the macro level of national government.

These initial findings relate to research undertaken in late 2002, prior to the transfer of all Glasgow's housing stock to the newly created Glasgow Housing Association Ltd (GHA) and the consequent changes to structure and working practices within Building Services.

\section{Knowledge Management Developments}

Many of the first wave of KM initiatives focused on interventions which attempted to convert tacit knowledge (that is, information that is not written down but kept 'in peoples' heads') to explicit knowledge (that is, information that can be coded and is objective and can be recorded in documents or in databases). For example, Nonaka and Takeuchi's four-stage model of knowledge conversion, the knowledge spiral, which was designed to explain how tacit knowledge and explicit knowledge interact to create knowledge and the framework for a learning organisation. Explicit knowledge, it is believed, can be embodied through the use of documents, diagrams and computer systems. ICTs can then be used to store and disseminate this knowledge. The problem of how to encode this tacit knowledge is seen as a key issue. Thus, ICTs in themselves can enhance and deliver radical opportunities to improve knowledgesharing processes.

However, many of these technology-focussed KM projects failed, primarily due to a lack of understanding of the difference between 'information' and 'knowledge' [1], [2], [3]. Organisations that relied on ICTs for managing knowledge, in fact, managed 
their intangible assets much like they had always managed their tangible assets. Many organisations who implemented so-called 'knowledge management solutions' found they failed to live up to their promise, since they focussed almost entirely on the technological aspects and ignored the human and organisational aspects. The use of corporate intranets, databases and datamining techniques are, indeed, useful tools for capturing explicit knowledge and routine work procedures but knowledge is dynamic, subjective and interpretive in nature (Malhotra 1997, cited in [4])

Technology cannot, in itself, make organisations more 'knowledgeable' [5]. Knowledge like information has meaning, however, knowledge unlike information relates to beliefs and commitment and knowledge unlike information relates to action [6]. Thus knowledge is contextual and dependent on a combination of elements.

Later developments in 'strategic' KM techniques have focussed on building an effective knowledge-sharing environment and on creating an infrastructure to "foster the exchange of knowledge in a community-oriented environment" (Ellis \& Tissen 1999 cited [4]). The emphasis in 'strategic' KM is on corporate culture and on social communities of employees. Thus we see an importance being placed on 'communities of practice' for sharing knowledge which

"reflect the way in which people actually work as opposed to the formal job descriptions or task-related procedures that are specified by the organization" [6:23].

In addition, 'communities of interaction' may need to be encouraged which span departmental and organisational boundaries to further promote knowledge sharing. Collaboration, knowledge sharing and self-organising teams are seen as key strategic goals at all levels of the organisation.

Other more 'organic' approaches to KM offer a typology and linguistic framework to observe and document how things are actually done and how knowledge is actually exchanged in practice. A more recent wave of KM theorists [7], [8] have, indeed, questioned the principles upon which much of the earlier KM literature had been based. Drawing on complexity theory, they point out the contradictions in attempting to manage and control knowledge that is so inextricably linked to the 'knowers', their minds, identities and beliefs. Indeed, Stacey (2001) goes on to question the ethics of attempting to do so, as:

"To talk of a corporation owning knowledge, managing knowledge, controlling knowledge, is to talk of corporations controlling the very identities of human persons" [7:3].

Managers need to realize that unlike information, knowledge is embedded in people and knowledge creation occurs in the process of social interaction [9]. Indeed, many writers have emphasised that only human beings can take the central role in knowledge creation and argue that computers are merely tools, however great their information processing capabilities my be. Knowledge is socially constructed and is subjective. People form the 'communities of practice' which preserve and create knowledge as well as creating a set of values and assumptions that form the basis of their working lives. Thus knowledge becomes culturally embedded and knowledge creation occurs as a process of social interaction. Technology can, indeed, help and support the dissemination of this knowledge but is not, in itself, a knowledge creator. A 'KM' solution is not, therefore, a matter of simply implementing a new ICT sys- 
tem, a "mission impossible" [10], but involves changing organisational structures and communication habits.

An over emphasis on the power of ICTs to capture and communicate knowledge ignores the social processes through which knowledge is validated. Indeed, it has been stated that "Knowledge Management is mostly Culture and People, with Technology thrown in" [11]. The human employee element and the way in which they use and interact with information are important [12]. Nevertheless, it is impossible to discount technology as a necessary underpinning of KM and some would argue [13], [14], [15] that developments in technology, the speed and connectivity this provides and the subsequent rise of the networked organisation, provided the catalyst for current KM strategies and applications. Successful KM strategies rely on the appropriate combination of people, processes and technology with an emphasis on environment, culture and self-organising communities of practice, organically sharing and creating knowledge. ICTs play their part in KM by providing an infrastructure to support and encourage knowledge sharing within a supportive organisational culture.

\section{KM as a Tool of E-government}

As with other management theories, fashions and methods designed and developed in the commercial sector, so KM is now beginning to make inroads into the public sector. However, as Milner [12] reminds us, quite often these models, theories and practices are implemented and applied without much thought being given to adapting them to the working patterns and practices of governments. One concern is that public sector organisations are rushing into large-scale investments in IT, making the same mistakes that characterised early KM projects in the private sector.

Public sector organisations on the whole are complex, hierarchical organisations. They are involved in a wide number of different relationships between, for example, policy makers, service providers, politicians and the general public. Moreover, increasingly, new relationships with outsourced functions and private-public partnerships are creating new ways of working and organising work. Thus there is wide scope for knowledge management applications and theory to be applied and tested. How do these various stakeholders share their knowledge and experience with the others?

The success or failure of KM projects in general rests on a number of different factors. These include a flexible organisational structure, a knowledge-friendly culture, motivated staff, multiple channels of knowledge transfer and senior management support as well as a technical infrastructure that can support successful knowledge sharing. They also need to be in line with the individual organisation and their culture and goals. KM projects are often focussed on providing the physical infrastructure to facilitate knowledge sharing and storage but what is of paramount importance is to encourage a 'climate of sharing'.

Experience from early adopter public sector organisations suggests that the success or failure of ICT supported KM projects rests on a number of different factors. Firstly, where knowledge can be explicitly stated and coded, ICT based KM systems are more likely to succeed, although, they still need to be supported by other factors. Secondly, there needs to be some sort of common understanding or amount of common knowledge between the groups participating in the project. Moreover, the indi- 
viduals must be willing to share their knowledge, to trust the other parties involved and the organisational culture must support and encourage knowledge sharing and knowledge creation.

In the public sector, the traditional hierarchical structure often exhibited is not conducive to, and may potentially hinder, successful KM implementation. Moreover, there appears to be an embedded culture of not sharing information and knowledge between departments in governments which in turn may lead to a difficulty in both the creation and maintenance of horizontal networks across organisations [16]. Indeed, the culture and operations within the public sector have been shown to hinder the development of inter-departmental relationships [17] and the potential to develop 'communities of interaction'. Additionally, achieving integrated public services may well be hindered by overt and covert issues of territory and power [18]. For KM to work, a focus needs to be placed upon the employee, for public servants to be treated as assets rather than tools of public service delivery [12] and a reconceptualisation of the public sector to a service oriented organisation. The dynamics for change towards a KM enabled public sector exhibit tensions between creating a commitment to an operating culture, where information sharing is the norm, and formal structures with little or no flows of information, characterised by 'turf wars' [18].

The most difficult barriers to overcome in implementing KM projects in the public sector concern the "cultures and contracts which serve to impede rather than support the collaborative and improvement focussed culture" (Milner 2000:76). Moreover, commitment to such projects from staff, as well as good local leadership and support, is needed if they are to succeed. Skills in change management are, therefore, required. In addition, the introduction of new ICT systems, designed to enhance knowledge sharing, needs to be implemented with thought, planning and the appropriate training and development of staff.

For the development of a new model of public service administration and service delivery, the creation of a successful information and knowledge-focussed organisational culture is necessary, indeed, some might say essential. The concepts of KM can be used as a strategy for change and innovation in the public sector and can be aligned with the goal of improving services and internal administrative processes, leading to more responsive and flexible organisations. KM has the potential to join-up organisations by promoting data sharing, avoiding duplication of effort and improving access to information and the way it is presented. However, the removal of traditional barriers and the promotion of knowledge sharing are necessary if a more knowledge driven organisational culture is to be created. Increased expectations and demands of citizens and those employed within the public sector in terms of easier and greater access to information are proving to be key drivers of KM development.

Within the UK, following the publication of the Modernising Government agenda, a programme of change and reform has begun to improve the efficiency and effectiveness of public services. A number of government policies aimed at information age' government have been put forward, for example, Modernising Government (1999) committed to modernising public services and having all public services delivered electronically by 2005 (which has subsequently been extended to 2008). Local authorities are expected to offer at least $25 \%$ of their services on-line by 2005 . Following this, various government initiatives have been implemented, such as the UKOnline portal to services, launched in September 1999. A key strategic goal is that government services will become more 'joined-up' around the needs of 'the customer'. This drive towards egovernment and a more citizen-focussed approach to the delivery 
of services is causing a rethinking of the processes of government. It also involves significant changes to the knowledge resources within governments. To facilitate such programmes as the on-line delivery of services, adequate access to information and knowledge resources are needed [19], [20].

In a further drive to modernise the internal processes of government, the Knowledge Network was established in October 2000 to support government departments in sharing knowledge and working on-line with others across government. The Knowledge Enhanced Government (KEG) programme was designed to examine key KM areas, such as knowledge capture, knowledge transfer, knowledge retention and enabling knowledge based community working between and across departments. A Knowledge Management National Project has recently been established in England to develop a consistent KM system to be used over all local authorities. However, it appears that the 'KM as technology' philosophy is being followed.

\section{Knowledge Sharing in Building Services?}

A study was undertaken to examine KM within Glasgow City Council's Building Services department - specifically the 'Design Team' of the department's Design, Build \& Project Management Division. Up until March 2003, the Design Team employed 102 staff, comprising Architects, Quantity Surveyors, Engineers, Clerks of Work and Administrative staff, who were responsible for the design, procurement and contractual issues associated with all council-owned major building maintenance projects and new build construction. The Design Team were specifically selected for this research because they are effectively consultants who sell their 'knowledge' to other client departments, in the shape of new building designs, specifications and technical drawings. This Design Team could be said to be a 'community of practice' sharing common understandings and knowledge within a particular environment. In addition, Building Services introduced a divisional approach to service delivery by creating six service departments. This structure was chosen to allow services to be more clearly defined for customer access ${ }^{1}$. Therefore, there were several divisions who needed to communicate information and ideas within the organisation.

The initial empirical research comprised a questionnaire distributed to 90 of the 102 staff employed in the Design Team division. The response rate was $43 \%$. The objectives of the questionnaire were to attempt to evaluate the culture of the division vis-a-vis knowledge sharing; to assess the role that management played in encouraging knowledge sharing and creation and to explore the impact of existing technology. This was supplemented by interviews with six questionnaire respondents who had indicated a willingness to take part in follow-up interviews.

The results of the survey showed a high number (44\%) of the staff claiming an understanding of KM and its meaning, and nearly all (85\%) believed that knowledge sharing could benefit an organisation. In exploring the impact of organisational culture with regard to knowledge sharing, the majority of the respondents, $44 \%$, perceived that management did not encourage knowledge sharing. With regard to man-

1 These were: Repairs \& Maintenance (DLO); Design, Build \& Project Management; Integrated Manufacturing; Training Services; Transport Services and Customer Services. 
agement's role in knowledge creation, the perceptions were almost identical. Once again, $44 \%$ of respondents considered that management did not promote knowledge creation within the department. Only $8 \%$ of respondents thought management actually encouraged knowledge creation. A key factor in KM project success is management support, which it appears, was not perceived as being in evidence to the staff within the division

Almost two-thirds of the respondents agreed that 'organizational culture' is the greatest inhibitor to knowledge sharing and a vast majority (87\%) that the 'knowledge is power' syndrome existed within the department. Exploring this question in greater detail through the follow-up interviews, it was discovered that a feeling of a 'blame culture' existed within Building Services. One interviewee even suggested that the fear of reprimand resulted in staff 'keeping their heads down'. Another interviewee highlighted the presence of a number of sub-cultures that he believed to exist within the Design Team, which created barriers to knowledge sharing. All interviewees agreed that the current situation required senior management intervention to reassure staff and promote openness and trust. These findings resonate with previous studies which have found this 'natural' inclination to hoard knowledge at every level of practically every organization (see for example a study by Martin (2000 \& 2003) on KM in local government in Australia [21] [22]). Moving to a KM culture means a profound shift from these ways of thinking [23], which it appeared at the time of this survey, was not present within this group.

The questionnaire also aimed to unpick some of the ideas around ICTs and KM. The vast majority (85\%) felt that the most important enabler of knowledge sharing was 'people'. However, the vast majority (82\%) thought that ICTs could assist knowledge sharing within the department. Thus we see from this sample, that technology as an aid to KM, rather than the means to KM, appears to be the case. Recent research has indeed shown that significant failure rates have been found with regard to KM technology projects where little attention is paid to the 'human element' and the relation between technology, knowledge processes and overall organisational performance [24].

The next stage was to investigate what software the staff had access to that might enable knowledge sharing. These are shown in the table below.

Table 1. Software availability

\begin{tabular}{|l|l|}
\hline SOFTWARE & $\mathbf{\%}$ \\
\hline Email & $100 \%$ \\
\hline Microsoft Office & $90 \%$ \\
\hline Intranet & $87 \%$ \\
\hline Internet & $72 \%$ \\
\hline CAD & $69 \%$ \\
\hline
\end{tabular}

However, the findings highlighted that around half the respondents with access to the Internet and Intranet either rarely used it (approximately once a week) or never (or 
only very occasionally) used it. This raises serious questions over staff utilisation of both applications which might have been used to promote knowledge sharing.

Exploring this theme in more detail, respondents were asked to give examples of how ICTs could assist knowledge sharing within their particular department. The respondents' examples are listed below in order of popularity of choice:

Table 2. Use of ICT supported knowledge tools

\begin{tabular}{|l|l|}
\hline ICT SUPPORTED KNOWLEDGE TOOL & $\%$ \\
\hline Staff briefings delivered through e-mail & $19 \%$ \\
\hline $\begin{array}{l}\text { Fully utilise Computer-Aided Design (CAD) system through sharing } \\
\text { designs, details and storage of drawings }\end{array}$ & $15 \%$ \\
\hline Improve storage and access to knowledge by use of shared databases & $15 \%$ \\
\hline Full utilisation of the Intranet by the department. FAQ pages & $10 \%$ \\
\hline Internet access for all staff & $7 \%$ \\
\hline IT software training & $7 \%$ \\
\hline Database with project review on feedback of successes and failures & $7 \%$ \\
\hline Improve communications generally & $7 \%$ \\
\hline Shared information distributed through the use of e-mail & $5 \%$ \\
\hline
\end{tabular}

It would appear, from the examples offered, that the existing technology is not fully utilized, in line with the previous table. Although it is informally recognised that individual and specialist knowledge exists within the team, this has not been explicitly captured or utilized and the full knowledge sharing capabilities of the CAD system, which was thought of as being a KM tool, are being ignored. 'Word of mouth' was more regarded as a more important way of sharing information and knowledge.

In summary, the research findings appear to indicate that the current levels of knowledge sharing and creation within the group are hampered by a number of factors. Firstly the organizational culture, in particular knowledge hoarding. Secondly, that management do not encourage the sharing or creation of knowledge. Thirdly, that there is a lack of trust and openness and the perception of a 'blame culture' which is not conducive to successful KM implementation. Finally, although staff do have good access to ICTs, which could allow them to share expertise, they are not using the technology to support and encourage knowledge sharing and creation.

The investigation found that the Department have invested large amounts of money in technology but this investment is only giving marginal returns in terms of enhancing the knowledge base of the organisation. Whilst the technology is in place, the current culture is inhibiting knowledge sharing and there are few, if any, processes available to promote knowledge creation. Moreover, management need to take a more proactive role in promoting a knowledge focused organizational culture, without which, any KM initiative becomes a 'mission impossible'. 
It has been stated that organisations should "hire smart people and let them talk to each other". Building Services employs and develops 'smart' people but the culture and processes need to be in place to encourage and enable them to talk to each other and share their expertise and knowledge.

\section{Conclusions and Further Research}

At this preliminary stage of reporting, the main ideas and themes in the literature are supported by the findings of this survey. There is an indication that taking a knowledge focus can improve the internal processes of local government and deliver a more efficient and 'joined up' service to citizens. However, in the rush to embrace KM, also comes the danger of rushing into introducing new technology without giving due consideration to the processes and, critically, the appropriate culture, to enable knowledge sharing, within and between departments and organisations. Without this knowledge sharing and creation, local authorities will be unable to achieve the desired levels of efficiency and effectiveness. A KM focus is even more critical for Building Services as they prepare for the massive changes and uncertainty brought about by the transfer of Glasgow's entire housing stock to the newly created GHA, in March 2003. Building Services are currently restructuring to meet the needs of the GHA and to face the future, more competitive, market place, where Building Services will have to tender, along with private contractors, for building and maintenance contracts.

We believe that what these preliminary findings have shown is that, although ICT enabled KM tools can be implemented, unless the users of the system have faith in it and are willing to use it to is full extent, the software itself cannot produce 'knowledge sharing'. What is needed is a corporate culture that encourages knowledge sharing and that sees KM as a way to enhance processes, improve communication flows and so build an atmosphere of trust, transparency and openness in decision-making. As a step towards achieving this, senior management are urged to provide richer communication regarding the strategic objectives and values of the organization in a way that is accessible to all employees. ICTs can indeed help in this and make the process easier but the 'human element' remains of prime importance.

\section{References}

1. Malhotra Y (1997) "Knowledge Management in Inquiring Organizations", proceedings of $3^{\text {rd }}$ Americas Conference on Information Systems, August 1997, pp 293-296

2. Hildebrand C (1999) "KM Gets Real", CIO Magazine, February 15

3. Hildebrand C (1999) "Making KM Pay Off", CIO Magazine, February 15

4. Schloetzer J (2000) "Managing the Intangible" [online] www.ecknowledgecentre.com

5. Hendriks PHJ (2001) "Many rivers to cross: from ICT to knowledge management systems" in Journal of Information Technology Vol 16, pp 57-72

6. Nonaka I and Takeuchi H (1995) The Knowledge Creating Company: How Japanese Companies Create the Dynamics of Innovation OUP, Oxford

7. Stacey R D (2001) Complex Responsive Processes in Organizations Routledge: London

8. McElroy M (2003) The New Knowledge Management, Butterworth-Heinemann

9. Sveiby K E (1997) The New Organizational Wealth, Berrett-Koehler 
10. Hislop D (2002) "Mission Impossible? Communicating and sharing knowledge via information technology", Journal of Information Technology, Vol 17 No. 3 pp 165-177

11. Liebowitz J (2000) Building Organisational Intelligence, CRC Press,: London

12. Milner E M (2000) Managing Information and Knowledge in the Public Sector, Routledge, London

13. Davenport T and Prusak L (1998) Working Knowledge: How Organisations Manage What They Know, Harvard Business School Press: Boston

14. Hansen M T, Nohria N and Tierney T (1999) "What's Your Strategy for Managing Knowledge?" Harvard Business Review, March-April, pp106-116

15. Skyrme D J (1999) Knowledge Networking: Creating the Collaborative Enterprise Buttterworth-Heinmann: Oxford

16. Bate SP and Robert G (2002) "Knowledge Management and Communities of Practice in the Private Sector: Lessons for Modernizing the National Health Service in England and Wales" in Public Administration Vol. 80 No 4 pp 643-663

17. Erridge A and Greer J (2002) "Partnerships and Public Procurement: Building Social Capital Through Supply Relations" Public Administration Vol. 80 No 4 pp 503-522

18. Bannister F (2003) "Turf Wars: The Hidden Menace" in proceedings of the $3^{\text {rd }}$ European Conference on e-Government, Trinity College Dublin

19. Cabinet Office (1999) Modernising Government, CM4310 Stationery Office, London

20. The Prime Minister's Office of Public Services Reform (2002) Reforming Our Public Services, March

21. Martin B (2002) Knowledge Based Organisations: Some emerging trends in local government in Australia paper presented to the $2^{\text {nd }}$ European Conference on Knowledge Management

22. Martin B (2003) "Knowledge Management and Local Government: Some Emerging Trends" in Asia Pacific Management Review Vol 8(1) pp 43-58

23. Stanyon T (1998) "It's Their Business to Know", Spotlight, Knowledge Management, December 1998/January 1999, pp10-19

24. Malhotra Y (2004) "Integrating Knowledge Management Technologies in Organizational Business Processes: Getting Real Time Enterprises to Deliver Real Business Performance" in Journal of Knowledge Management Q3 pp 1-24 